\title{
An unusual case of dysphagia
}

Plummer-Vinson syndrome was first described in 1912 [1], but seems to be extremely uncommon nowadays. We present the case of a 48-year-old woman referred for evaluation of dysphagia of 8 years' duration, which was worsening in frequency and intensity. The dysphagia initially involved only solids, but the patient now reported difficulty swallowing liquids as well. She also reported a weight loss of $10 \mathrm{~kg}$ over the past 2 years. The past medical history was essentially negative; medication intake included occasional iron supplements. Physical examination revealed no major abnormalities except for general pallor. A complete blood count showed a hemoglobin of $7.1 \mathrm{mg} / \mathrm{dL}$ and a mean corpuscular volume of 55.

A barium swallow revealed circumferential narrowing of the cervical esophagus just below the cricopharyngeal muscle, at the level of the C4 vertebra ( $\bullet$ Fig. 1). This was followed by an endoscopic gastroduodenoscopy (EGD), which showed a smooth, circular, whitish narrowing at $20 \mathrm{~cm}$ from the scope entry, suggestive of a web. The scope could not be passed further ( $\bullet$ Fig. 2).

Endoscopic dilation was performed under fluoroscopy, using dilators with serially increasing diameters. The web was easily disrupted without complications. The postendoscopic course was uneventful with resolution of the dysphagia, and the patient was discharged. She was followed up for 3 years and there was no recurrence of dysphagia or anemia.

Plummer-Vinson syndrome affects mostly women of Caucasian origin. The presenting symptom, dysphagia, is usually painless and intermittent or progressive. The most important possible etiologic factor is iron deficiency; this hypothesis is supported by improvement of the dys-

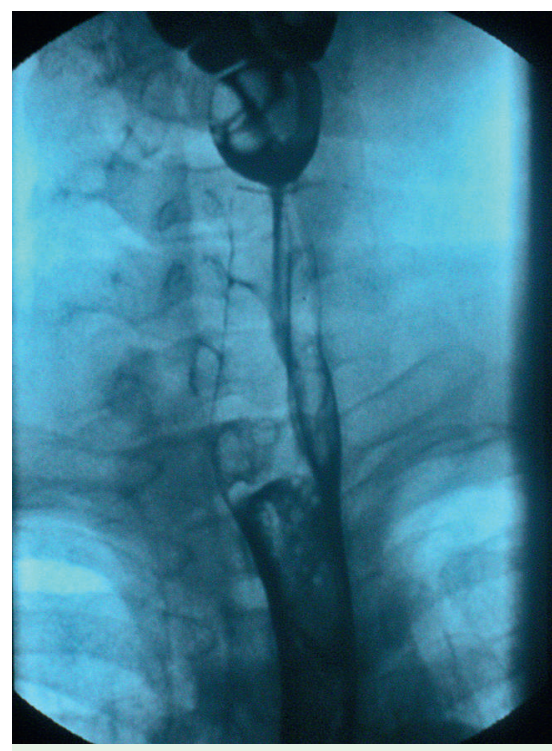

Fig. 1 Pretreatment barium swallow showing proximal narrowing in the cricopharyngeal area.

phagia after iron therapy [2]. Many other causes have also been proposed. Management of Plummer-Vinson syndrome is straightforward. Iron replacement should be continued until normalization of the hematocrit and ferritin levels. Although iron therapy may lead to considerable improvement of dysphagia [3], this is not the case in patients with longstanding disease; they usually require mechanical dilation [4]. One session is usually enough to give long-term relief like in our case, but, rarely, multiple sessions may be warranted.

Endoscopy_UCTN_Code_CCL_1AB_2AC_3AD

\section{Issa, W. Yassine}

Department of Gastroenterology and Hepatology, Rafik Hariri University Hospital, Beirut, Lebanon

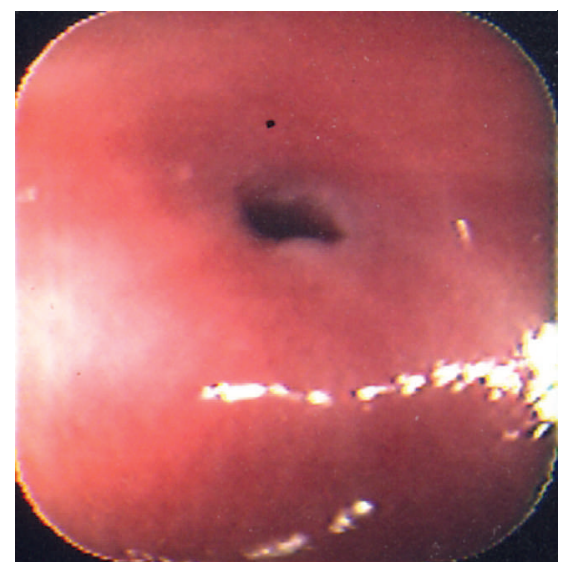

Fig. 2 Esophagogastroduodenoscopy revealing a smooth, circular web in the proximal esophagus.

\section{References}

1 Plummer HS. Cardio spasm: with a report of 40 cases. JAMA 1908; 51: 549-554

2 Atmatzidis K, Papaziogas B, Pavlidis T et al. Plummer-Vinson syndrome: case report. Dis Esophagus 2003; 16: 154-157

3 Hoffman RM, Jaffe PE. Plummer-Vinson syndrome. A case report and literature review. Arch Intern Med 1995; 155: 2008 2011

4 Beyler AR, Yurdaydin C, Bahar K et al. Dilation therapy of upper esophageal webs in two cases of Plummer-Vinson syndrome. Endoscopy 1996; 28: 266-267

Bibliography

DOI 10.1055/s-0029-1214656

Endoscopy 2009; 41: E120

(c) Georg Thieme Verlag KG Stuttgart · New York . ISSN 0013-726X

\section{Corresponding author}

\section{Issa, MD}

Division of Gastroenterology and Hepatology Rafik Hariri University Hospital

Jnah - Beirut

Lebanon

Fax: +961-1-737377

Fax: iyadissa71@gmail.com 